\title{
Primary Dengue Infection in Patients Requiring Hospitalization During an Outbreak in a Low Incidence Mexican Region
}

\author{
María Elena Cárdenas-Perea, ${ }^{1}$ Lilian Karem Flores-Mendoza, ${ }^{2}$ Irma Pérez-Contreras, ${ }^{3}$ \\ María Alicia Díaz-Orea, ${ }^{4}$ Eduardo Gómez-Conde, ${ }^{4}$ Paulina Cortés-Hernández, \\ Julio Reyes-Leyva, ${ }^{6}$ Gerardo Santos-López, ${ }^{6}$ and Francisca Sosa-Jurado ${ }^{6}$
}

\begin{abstract}
Background: Dengue manifestations can range from subclinical to fatal. The study of factors that influence dengue's clinical severity can provide information to potentially limit or predict severe cases. Secondary infection (SI) with a different dengue serotype has been recognized as an important determinant of severity. However, severe dengue (SD) manifestations, including shock, can happen during primary infection (PI) too and the mechanisms involved are less understood. To characterize the severe manifestations associated to PI, we distinguished between primary and secondary dengue cases in hospitalized patients from a region of low and recent dengue incidence in central Mexico. This region can serve as a model for dengue's behavior as it spreads to new areas worldwide.

Methods: Dengue-specific immunoglobulin M (IgM) and $\operatorname{IgG}$ concentrations were measured in the serum of 78 hospitalized patients with dengue hemorrhagic fever, and their ratios were used to discriminate between PI and SI, as recommended by World Health Organization. Clinical and laboratory manifestations were compared between PI and SI.

Results and Conclusions: PI was detected in $23 \%$ of hospitalized dengue cases, a proportion similar to that reported in high-incidence regions in Mexico. PI was more frequent in 16- to 40-year-olds, and was absent in patients older than 60 years. Only dengue with warning signs and SD were present in the studied population of hospitalized patients, and case frequency decreased with clinical severity both in PI and SI groups. No significant differences in demographics, laboratory tests, or symptoms were found between PI and SI, which illustrates that cases requiring hospitalization during outbreaks can be severe, even if they are PI. This information can help plan for sanitary contingencies in places where dengue is recently emergent and numerous PI cases are expected. The mechanisms involved in PI clinical severity need to be studied further.
\end{abstract}

Keywords: dengue primary infection, dengue outbreak, dengue $\operatorname{IgG}$ and $\operatorname{IgM}$

\section{Introduction}

D ENGUE IS A COMMON infection worldwide, with 4.0 billion people (half the world's population) currently at risk (Brady et al. 2012). It is caused by dengue virus (DENV), an arbovirus (arthropod-borne virus) with four serotypes (DENV-1 to 4) that circulate periodically (Wash et al. 2015). Because of its recent and rapid spread all over the world, DENV is considered an emerging pathogen and it is endemic in at least 128 countries (Brady et al.

\footnotetext{
${ }^{1}$ Departamento de Microbiología y Parasitología, Facultad de Medicina de la Benemérita Universidad Autónoma de Puebla, Puebla, Mexico.

${ }^{2}$ División de Ciencias e Ingeniería, Departamento de Ciencias Químico Biológicas y Agropecuarias, Universidad de Sonora, Navojoa, México.

${ }^{3}$ Departamento de Salud Pública, Facultad de Medicina de la Benemérita Universidad Autónoma de Puebla, Puebla, México.

${ }_{5}^{4}$ Departamento de Inmunología, Facultad de Medicina de la Benemérita Universidad Autónoma de Puebla, Puebla, México

${ }^{5}$ Laboratorio de Biología Celular, Centro de Investigación Biomédica de Oriente del Instituto Mexicano del Seguro Social en Metepec, Puebla, México.

${ }^{6}$ Laboratorio de Biología Molecular y Virología, Centro de Investigación Biomédica de Oriente del Instituto Mexicano del Seguro Social en Metepec, Puebla, México.
} 
2012). Nearly 60 million symptomatic dengue infections occur each year, resulting in $\sim 10,000$ deaths (Stanaway et al. 2016).

To aid clinical decisions, the World Health Organization (WHO) issued guidelines for the classification of dengue manifestations in 1997 and 2009 (WHO 1997, 2009a). The 1997 classification grouped symptomatic cases into three categories: undifferentiated fever, dengue fever (DF), and dengue hemorrhagic fever (DHF). DHF was further classified into severity grades (I-IV), with the last two grades defined as dengue shock syndrome (DSS) (WHO 1997). Because many clinically severe cases did not qualify as DHF, new guidelines were issued in 2009 , now grouping cases into dengue without warning signs, dengue with warning signs (DWWS), and severe dengue (SD) that includes DSS (WHO 2009a). The advantages of the new classification have been discussed (Abello et al. 2016, da Silva et al. 2018); however, the 1997 classification remains in use among some clinicians and in literature.

A secondary infection (SI) with a different DENV serotype (heterotypical infection) has been recognized as a contributor to severity, related to the phenomenon of antibody-dependent infection enhancement. In this immunopathological phenomenon immunoglobulin $\mathrm{G}$ ( $\mathrm{IgG}$ ) immune complexes mediate the worsening of dengue by favoring viral replication, with the consequent release of proinflammatory cytokines and chemokines that increase vascular permeability and can lead to shock (Halstead 2014). However, severe clinical manifestations, including DSS, have also been reported during primary infection (PI) with some DENV serotypes (Soo et al. 2016) and the mechanisms involved in severity remain poorly understood. The relative risk of SD in SI versus PI has been estimated as ranging from 2 to 7 (Halstead and Wilder-Smith 2019).

PI and SI can be discriminated by analyzing denguespecific immunoglobulins during the acute phase of the infection (first 8 days of symptoms). In PI, IgM is the first isotype to appear, detectable in $50 \%$ of patients by day 3 and in $80 \%$ by day 5 after symptom onset, followed by IgG detectable at low levels around day 10 (WHO 2009b, Halstead and Wilder-Smith 2019). In SI, IgG is the dominant isotype present at high levels from symptom start, with low or undetectable IgM levels during the acute phase (WHO 2009b).

In the last 10 years, the four DENV serotypes have circulated in Mexico. Similar to other world regions, DENV has rapidly spread to nonendemic regions of the country (Dantés et al. 2014) and DHF has increased (Dantés et al. 2014, SSA 2016), especially in the young, including children (Dantés et al. 2014, Torres-Galicia et al. 2014).

Disease severity during PI has not been evaluated in regions of low DENV incidence where this pathogen is emergent. These regions could present numerous PI cases during outbreaks, as most population has not been exposed to DENV. Characterization of PI severity in this scenario can aid the planning for dengue-related sanitary emergencies in regions of recent dengue spread, which are predicted to increase because of population dynamics and climate change. For this reason, we studied the proportion of dengue PI and SI and compared their clinical manifestations in hospitalized patients in a region of recent and low dengue incidence in central Mexico.

\section{Materials and Methods}

\section{Ethical statement}

This research was approved by the Local Committee of Ethics and Health Research of the Instituto Mexicano del Seguro Social (IMSS); registry numbers R-2011-210324, R-2011-2103-29 and of the Benemérita Universidad Autónoma de Puebla, registry number100336999-VIEPBUAP2018.

\section{Patients and location}

We conducted a retrospective study that included all the patients with confirmed dengue that required hospitalization in the General Hospital of Zone No. 5 (HGZ5), IMSS, during the dengue outbreak between June 11 and December 15, 2015 (6 months). Patients were referred from primary care with dengue symptoms and marked thrombocytopenia and neutropenia to the concentration hospital mentioned previously. This hospital is a public health care institution located in Metepec, Atlixco, Puebla, that serves the majority of the population of the Atlixco-Izucar de Matamoros Valley $\left(18^{\circ} 54^{\prime} 31^{\prime \prime} \mathrm{N} 98^{\circ} 27^{\prime} 55^{\prime \prime} \mathrm{W}\right)$. The region is located at an altitude 1282-1834 meters above sea level (masl) and includes two cities: Atlixco (132,827 inhabitants) and Izucar de Matamoros (41,042 inhabitants) and the agricultural valley between/around them (INEGI 2017).

\section{Dengue diagnosis}

DENV infection was confirmed upon hospitalization in all patients, by qualitative identification of DENV-specific antibodies using Dengue Duo IgM and IgG Capture enzymelinked immunosorbent assay (ELISA) (PanBio Pty Ltd., Brisbane, Australia) and by the detection of the nonstructural protein 1 (NS1) antigen of DENV (Platelia, Bio-Rad, Hercules, CA) in sera.

\section{Clinical data}

Blood samples were processed in the hospital's certified clinical laboratory, in a Cell-Dyn Emerald Hematology Analyzer (Abbott Laboratories, IL) for blood biometrics and in a Dimension RxL Max Integrated Chemistry System (Siemens Healthcare $\mathrm{GmbH}$, Erlangen, Germany) for blood chemistry, liver function tests, and electrolytes. Abdominal ultrasound and other tests were carried out according to standard hospital procedures.

\section{Quantitative determination of dengue $\lg G$ and $\lg M$ in sera and criteria for discrimination of PI versus SI}

To discriminate between PI and SI, DENV-specific IgG and IgM were quantified with commercial ELISA kits (DRG International, Inc., Springfield, NJ) in sera samples obtained at hospital admission and stored at $-80^{\circ} \mathrm{C}$ until use. Patients who had positive $\operatorname{IgM}$ and negative IgG were classified as PI, whereas patients with negative $\operatorname{IgM}$ and positive $\operatorname{IgG}$ were classified as SI. In patients with positive IgM and positive $\mathrm{IgG}$, we used a ratio of $\mathrm{IgM} / \mathrm{IgG} \geq 1.2$ for PI and $\mathrm{IgM} / \mathrm{IgG}$ $<1.2$ for SI, at 1:100 sera dilution, as suggested by the WHO (2009b). 
Table 1. Demographics and Diagnostic Data of Dengue Hemorrhagic Fever in 78 Hospitalized Patients from the Valley of Atlixco-Izucar de Matamoros, Puebla, Mexico

\begin{tabular}{lcc}
\hline & $\mathrm{n}(\% \text { of total })^{\mathrm{a}}$ & $\mathrm{p}$ \\
\hline Gender & & \\
Female/male & $41(52.6) / 37(47.4)$ & 1.000 \\
Average age in years (95\% CI) & $39.6(35.2-44.0)$ & \\
Groups by age and gender F/M & $7(9.0) / 5(6.4)$ & \\
$7-15$ & $15(19.2) / 16(20.5)$ & 0.906 \\
$16-40$ & $12(15.4) / 11(14.1)$ & $<0.01$ \\
$41-60$ & $7(9.0) / 5(6.4)$ & \\
$>60$ & $52(66.6)$ & $<0.01$ \\
Patients admitted during the early or late acute phase & \\
Early (1-4 days) & $26(33.4)$ & \\
Late (5-8 days) & $4.0(3.8-4.4)$ & \\
Average days from symptom onset to admission (95\% CI) & $40(51.2)$ & \\
Cases classified according to 1997 Dengue guidelines & $24(30.8)$ & \\
DHF-I & $14(18.0)$ & \\
DHF-II & $0(0.0)$ & \\
DHF-III & $78(100.0)$ & \\
DHF-IV & & \\
Total & $0(0.0)$ & \\
Cases classified according to 2009 Dengue guidelines & $67(85.9)$ & \\
Dengue, without warning signs & $11(14.1)$ & \\
Dengue, with warning signs (DWWS) & $78(100)$ & \\
Severe dengue (SD) & & \\
Total &
\end{tabular}

${ }^{a}$ Except when indicated otherwise, for example for the average age and average days from onset to admission.

${ }^{\mathrm{b}}$ The acute phase includes days 1-8 after symptom onset.

CI, confidence interval; DHF, dengue hemorrhagic fever.

\section{Statistical analysis}

Frequencies, percentages, averages, confidence intervals, Student's $t$, chi-squared and Fisher's exact tests were calculated in IBM SPSS Statistics V21.0 (IBM Corp., Armonk, NY). Significant differences were considered at $p<0.05$.

\section{Dengue classifications}

DHF grades I and II were infections without signs of shock, grade III was impending shock, and grade IV was profound shock, as stated in the WHO 1997 dengue guidelines (WHO 1997). DWWS and SD were defined according to WHO (2009a).

\section{Results}

We studied PI versus SI during the 2015 dengue outbreak in the valley of Atlixco-Izucar, Mexico. At admission, patients were classified according to WHO (1997) as that classification was in use at the studied hospital. All patients had DHF: $51.2 \%$ classified as DHF-I, $30.8 \%$ as DHF-II, $18 \%$ as DHF-III, and no patients had DHF-IV. For this study, we retrospectively reclassified patients according to the 2009 guidelines (WHO 2009a): $85.9 \%$ presented DWWS and $14.1 \%$ presented SD (Table 1 ).

We measured the dengue-specific immunoglobulin ratio during the acute phase, in the 78 DHF samples obtained at hospital admission. Most patients had IgM (-) and IgG (+) or IgM (+) and IgG (+) (Table 2). A total PI of $23 \%$ (95\% confidence interval $[\mathrm{CI}]=14-32$ ) was found in the studied population: 1 patient $(1.3 \%)$ qualified as PI because he presented only $\operatorname{IgM}$ with no $\operatorname{IgG}$, whereas the other 17 patients $(21.7 \%$ ) qualified using the $\mathrm{IgM} / \mathrm{IgG}$ ratio $\geq 1.2$ (Table 2). Regarding SI, 19 patients $(24.4 \%)$ were detected with the $\operatorname{IgM} / \operatorname{IgG}$ ratio < 1.2 , and other $41(52.6 \%)$ with $\operatorname{IgM}(-) /$ $\operatorname{IgG}(+)$, for a total SI of $77 \%$ (Table 2). The frequency of dengue-specific IgG levels $\geq$ average was the same in PI and SI patients. IgM was detected significantly more in PI (Table 2).

PI was more frequent in 16- to 40-year-olds (61.1\%), and it was absent in patients $\geq 60$ years (Table 3 ). DHF-I predominated in both PI and SI groups, whereas DHF-III was the least frequent severity grade in both groups (Table 3). When reclassified by the 2009 guidelines, $83.3 \%$ of patients with PI presented DWWS, similar to $86.7 \%$ of patients with SI (Table 3). Among PI patients, $55.5 \%$ were admitted during the late acute phase versus $26.7 \%$ of patients with SI (Table 3). No significant differences in symptoms, hematological or biochemical data were detected between patients with PI or SI (Table 4).

\section{Discussion}

Since 1978, dengue has been endemic in the tropical and subtropical areas of Mexico, but incidence has remained low in central Mexico. This is because climate/altitude limit the spread of dengue vectors to the most densely populated Mexican cities in central Mexico (located at $>2000 /$ masl), despite being surrounded by endemic areas (Dantés et al. 2014). We studied dengue in the valley of Atlixco-Izucar, located in the state of Puebla in central Mexico $(\sim 1500$ / masl). With a dry tropical climate most of the year and 


\section{Table 2. Dengue-Specific Immunoglobulin Profiles Used for the Classification of Primary and Secondary Dengue Infection in Hospitalized Patients with Dengue from the Valley of Atlixco-Izucar De Matamoros, Puebla, Mexico}

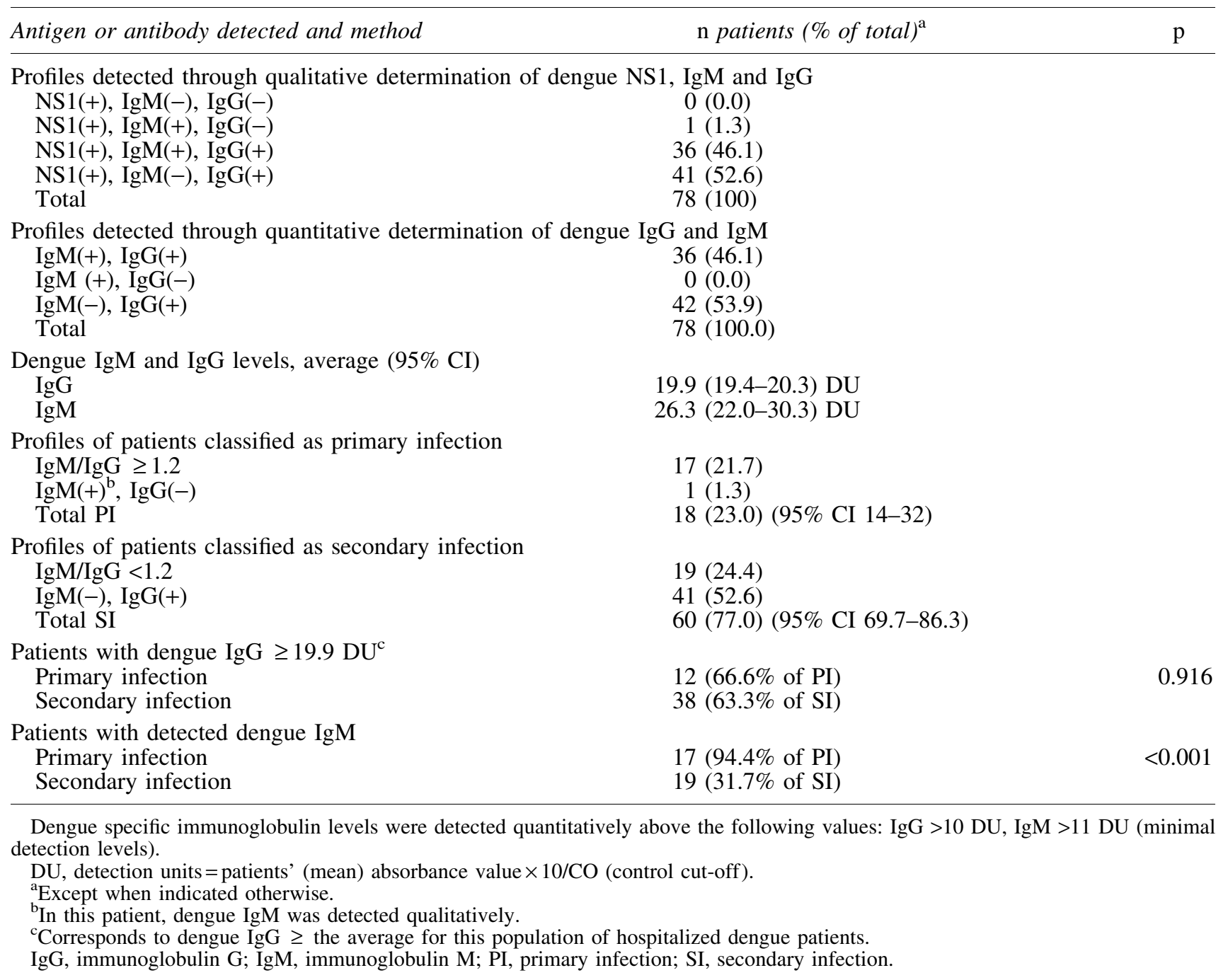

limited by highlands, this valley represents a transition zone between places of low and high dengue incidence. According to the Mexican Ministry of Health, during 2015-2016, the state of Puebla had an incidence of 0.01-13.1 dengue cases per 100,000 inhabitants, although it borders the states of Morelos and Guerrero, which have much higher incidences, ranging from 26.2 to 39.3 cases per 100,000 (SSA 2016).

There have been three recent and well-documented dengue outbreaks in the Atlixco-Izucar Valley: 2009-2010, when serotype DENV-1 prevailed (Vázquez-Pichardo et al. 2011); 2012-2013 dominated by DENV-2 (SSA 2014); and 2015 when DENV-1 was again more frequent, and DENV-4 was reported for the first time in the region (SSA 2016). Here we analyzed the rate of PI in 78 patients with dengue that required hospitalization during the last documented outbreak in the region. We included all the patients with confirmed dengue, admitted during the entire outbreak to the concentration hospital that serves most of the population of the Valley. The number of patients was only limited by the low dengue incidence in the region.
We used the recommendation to discriminate PI from SI with an IgM/IgG ratio >1.2 (WHO 2009b) in samples obtained in the acute phase (at hospital admission). With this strategy, we found $23 \%(95 \% \mathrm{CI}=14-32)$ PI in the studied population of hospitalized patients (Table 2). This is similar to the PI of $29.8 \%(95 \% \mathrm{CI}=18.8-40.8)$ reported previously in DHF patients from a Mexican region long endemic and with high DENV incidence (state of Veracruz, 26.18-39.23 dengue cases/100,000 inhabitants in 2015-2016) (SSA 2016). It should be noted, however, that the PI rate that we calculated does not reflect overall PI as we studied only dengue cases that required hospitalization. The rate of PI considering all dengue cases has been scarcely reported for Mexico (Posadas-Mondragón et al. 2017); and a different study design would be needed to compare overall PI in lowversus high-incidence Mexican regions.

PI in other world regions has been reported at $31 \%$ and $29 \%$ in Brazilian patients with DHF or DF/DHF (Guilarde et al. 2008), and at $44.7 \%$ in Sri Lankan children (Bodinayake et al. 2018), whereas meta-analyses have calculated $36.6 \%$ of PI in DHF for Southeast Asia and $10.6 \%$ for Latin America 
Table 3. Demographics and Dengue Classification of Hospitalized Patients with Primary Versus Secondary Dengue Infection from the Valley of Atlixco-Izucar de Matamoros, Puebla, Mexico

\begin{tabular}{|c|c|c|c|}
\hline & $P I$ & SI & $\mathrm{p}$ \\
\hline \multicolumn{4}{|l|}{ Gender, $n$ ( $\%$ of group) } \\
\hline Female & $12(66.6)$ & $29(48.8)$ & \multirow[t]{3}{*}{0.191} \\
\hline Male & $6(34.4)$ & $31(52.2)$ & \\
\hline Total & $18(100.0)$ & $60(100.0)$ & \\
\hline \multicolumn{4}{|l|}{ Age in years } \\
\hline Range & $7-60$ & 8-89 & \multirow[b]{2}{*}{0.191} \\
\hline Average $(95 \% \mathrm{CI})$ & $34.3(26.6-42.0)$ & $41.2(35.9-46.5)$ & \\
\hline \multicolumn{4}{|l|}{ Groups by age, $n$ (\% of group) } \\
\hline $7-15$ & $3(16.7)$ & $9(15.0)$ & 1.00 \\
\hline $16-40$ & $11(61.1)$ & $20(33.3)$ & \multirow{4}{*}{$\begin{array}{l}0.033 \\
0.561 \\
0.048\end{array}$} \\
\hline $41-60$ & $4(22.2)$ & $19(31.7)$ & \\
\hline$>60$ & $0(0.0)$ & $12(20.0)$ & \\
\hline Total & $18(100.0)$ & $60(100.0)$ & \\
\hline \multicolumn{4}{|c|}{ Patients admitted during the early or late acute phase, $n$ ( $\%$ of group) } \\
\hline Early (1-4 days) & $8(44.5)$ & $44(73.3)$ & \multirow[t]{3}{*}{0.043} \\
\hline Late (5-8 days) & $10(55.5)$ & $16(26.7)$ & \\
\hline Total & $18(100.0)$ & $60(100.0)$ & \\
\hline Average days from symptom onset to admission (95\% CI) & $4.0(3.3-4.8)$ & $3.8(3.5-4.3)$ & 0.658 \\
\hline \multicolumn{4}{|c|}{ Cases classified according to 1997 Dengue guidelines, $n$ (\% of group) } \\
\hline DHF-I & $11(61.2)$ & $29(48.3)$ & 0.424 \\
\hline DHF-II & $4(22.2)$ & $20(33.3)$ & 0.561 \\
\hline DHF-III & $3(16.6)$ & $11(18.4)$ & \multirow{2}{*}{1.00} \\
\hline DHF-IV & $0(0.00)$ & $0(0.00)$ & \\
\hline Total & $18(100.0)$ & $60(100.0)$ & \\
\hline \multicolumn{4}{|c|}{ Cases classified according to 2009 Dengue guidelines, $n$ (\% of group) } \\
\hline Without warning signs & $0(0.00)$ & $0(0.00)$ & \multirow{3}{*}{$\overline{0.709}$} \\
\hline With warning signs & $15(83.3)$ & $52(86.7)$ & \\
\hline Severe dengue & $3(16.7)$ & $8(13.3)$ & \\
\hline Total & $18(100.0)$ & $60(100.0)$ & \\
\hline
\end{tabular}

(Soo et al. 2016). The low PI suggested for Latin America needs confirmation with more studies. In a retrospective study that analyzed 30 years of fatal dengue cases in Brazil, deaths were observed significantly more in PI than in SI (Guerra-Nunes et al. 2018), supporting that PI can be severe.

Despite the recent dengue spread to the Atlixco-Izucar Valley, most of the patients requiring hospitalization during this outbreak had a previous dengue infection (77\% SI), possibly from previous outbreaks in the region. This behavior was expected as SI entails a higher risk of severity than PI (Halstead and Wilder-Smith 2019).

Overall, case frequency decreased with disease severity, but the distribution of cases throughout the severity spectrum was not different between PI and SI with either of the two WHO classifications (Table 3). This is compatible with results from Thailand where PI and SI were similar between DHF-I and DHF-II (Wichmann et al. 2004). In addition, we found a good agreement in case classification with the 1997 and 2009 WHO guidelines, similar to a recent report (da Silva et al. 2018).

Our study detected more PI in the young, in general agreement with studies in other countries, where PI has been detected more frequently in children than in adults (Bodinayake et al. 2018). However, the most frequent age range for PI in our study (16-40 years) corresponds to productive age. This is likely related to: (i) the low incidence in the region and (ii) the opportunity of exposition to the vector: the AtlixcoIzucar Valley is an agricultural region where workers are exposed to mosquitoes in the fields. An important advantage of studying severe PI in a low-incidence region is that PI can be found at diverse ages, whereas in high-incidence regions PI is almost limited to children.

The average number of days from symptom onset to hospital admission was not different between PI and SI groups (Table 3). Thus, samples used to discriminate between PI and SI were obtained equally early during the acute phase. Half the PI patients were hospitalized in the late acute phase (5-8 days after onset) versus only a quarter of SI patients (Table 3). This could reflect that PI patients took slightly longer to seek medical attention, because they were not familiar with dengue symptoms. Alternatively, there could be an underestimation of PI among patients evaluated in the early acute phase: because we did not evaluate the progression of the immunoglobulin profile, we cannot rule out that a minority of patients evaluated very early in the acute phase had higher IgM levels a few days later. However, the presence of $\operatorname{IgG}$ in these patients early in the acute phase strongly suggests SI; thus, the underestimation of PI in this group is unlikely.

Exanthema, epistaxis, and gingival bleeding tended to be more frequent in SI patients (Table 4), whereas plasma leakage and petechiae were observed at similar percentages in PI and SI (Table 4), and ascites and mottled skin were not present in PI (Table 4).

Using published criteria for clinical assessment (Tomashek et al. 2018), 27.7\% of our patients with PI qualified as 
Table 4. Clinical and Laboratory Parameters of Hospitalized Patients with Primary Versus Secondary Dengue from the Valley of Atlixco-Izucar de Matamoros, Puebla, México

\begin{tabular}{|c|c|c|c|c|}
\hline & $\begin{array}{l}\text { Primary } \\
\text { infection }\end{array}$ & $\begin{array}{l}\text { Secondary } \\
\text { infection }\end{array}$ & $\mathrm{p}$ & Normal values \\
\hline \multicolumn{5}{|l|}{ Laboratory parameters, average $(95 \% \mathrm{CI})$} \\
\hline Temperature $\left({ }^{\circ} \mathrm{C}\right)$ & $38.8(38.3-39.3)$ & $38.9(38.7-39.3)$ & 0.562 & $37^{\circ} \mathrm{C}$ \\
\hline$\%$ Hematocrit for age $7-15$ years & $45.4(33.2-57.5)$ & $45.3(40.8-49.7)$ & 0.980 & $40^{\mathrm{a}}$ \\
\hline$\%$ Hematocrit, females & $42.8(38.8-45.9)$ & $43(41.5-44.5)$ & 0.893 & $42.4^{\mathrm{b}}(41.2-43.4)$ \\
\hline$\%$ Hematocrit, males & $48(45-50)$ & $49.2(47.3-51)$ & 0.587 & $47.3^{\mathrm{b}}(45.7-48.8)$ \\
\hline Platelets, $10^{3} / \mu \mathrm{L}$ & $40.1(25.6-54.6)$ & $30(25.2-36.1)$ & 0.215 & $150-400$ \\
\hline Leukocytes, $10^{3} / \mu \mathrm{L}$ & $4.0(3.4-4.8)$ & $4.3(3.9-4.7)$ & 0.505 & $4.2-10.8$ \\
\hline Lymphocytes, $10^{3} / \mu \mathrm{L}$ & $1.3(0.94-1.70)$ & $1.5(1.29-1.70)$ & 0.419 & $1.2-3.8$ \\
\hline Neutrophils, $10^{3} / \mu \mathrm{L}$ & $2.45(1.75-3.15)$ & $2.64(2.11-3.16)$ & 0.719 & $1.8-7.0$ \\
\hline ALT in IU/L & $126(83-168)$ & $98(77-119)$ & 0.191 & $16-63$ \\
\hline AST in IU/L & $177(112-243)$ & $133(108-158)$ & 0.194 & $15-37$ \\
\hline Albumin in $\mathrm{g} / \mathrm{dL}$ & $3.1(2.9-3.3)$ & $2.9(2.7-3.0)$ & 0.060 & $3.4-5.0$ \\
\hline Calcium in $\mathrm{mg} / \mathrm{dL}$ & $7.7(7.6-7.9)$ & $7.9(7.7-8.0)$ & 0.290 & $8.5-10.1$ \\
\hline \multicolumn{5}{|l|}{ Symptoms/signs, $n$ (\% of group) } \\
\hline Fever, cephalea, arthralgia, retroocular pain, myalgia & $18(100)$ & $60(100)$ & 1.00 & - \\
\hline Trombocytopenia & $6(33.3)$ & $20(33.3)$ & 0.684 & $>5.0-10 \times 10^{4} \mu \mathrm{L}$ \\
\hline Moderate trombocytopenia ${ }^{c}$ & $7(38.9)$ & $29(48.3)$ & & $2.0-5.0 \times 10^{4} / \mu \mathrm{L}$ \\
\hline Severe trombocytopenia ${ }^{c}$ & $5(27.8)$ & $11(18.4)$ & & $<2.0 \times 10^{4} / \mu \mathrm{L}$ \\
\hline Total & $18(100)$ & $60(100)$ & & \\
\hline Hypoalbuminemia & $17(94.4)$ & $57(95)$ & 1.00 & $<3.4 \mathrm{~g} / \mathrm{dL}$ \\
\hline Hypocalcemia & $18(100)$ & $57(95)$ & 1.00 & $<8.0 \mathrm{mg} / \mathrm{dL}$ \\
\hline Exantema & $1(5.6)$ & $12(20)$ & 0.278 & \\
\hline Plasma leakage & $12(66.7)$ & $31(51.6)$ & 0.292 & \\
\hline Petechiae & $10(55.5)$ & $30(50)$ & 0.790 & \\
\hline Ecchymosis & $2(11.1)$ & $3(5.0)$ & 0.325 & \\
\hline Ascites & $0(0.0)$ & $2(3.3)$ & 1.00 & \\
\hline Mottled skin & $0(0.0)$ & $2(3.3)$ & 1.00 & \\
\hline Gingival bleeding & $2(11.1)$ & $15(25)$ & 0.213 & \\
\hline Epistaxis & $2(11.1)$ & $16(26.7)$ & 0.216 & \\
\hline Hematemesis & $1(5.5)$ & $5(8.3)$ & 0.658 & \\
\hline Melena/blood in stool & $1(5.5)$ & $3(5.0)$ & 1.00 & \\
\hline
\end{tabular}

${ }^{\text {a }}$ Normal hematocrit value at altitude 2,200/masl (López-Santiago 2016).

${ }^{b}$ Normal hematocrit values at altitude 970-1923/masl (Trompetero-González et al. 2015).

${ }^{\mathrm{c}}$ According to Tomashek et al. (2018).

ALT, alanine transaminase; AST, aspartate transaminase; masl, meters above sea level.

severe thrombocytopenia and $38.8 \%$ had moderate thrombocytopenia, without significant differences compared with SI (Table 4). We observed a decrease in albumin, along with elevated alanine transaminase (ALT) and aspartate transaminase (AST) in both PI and SI (Table 4) denoting liver inflammation, which has been associated with severity (Oliveira et al. 2016, Posadas-Mondragón et al. 2017); however, there were no cases of acute hepatitis marked by $>10$ times ALT increase, unlike in other studies (Souza et al. 2004). It has been reported that $\mathrm{Ca}^{2+}$ levels correlate with disease severity, with hypocalcemia being more prevalent in DHF than in DF (Constantine et al. 2014). Our results agree with that report, although hypocalcemia was found at a similar percentage in PI and SI (Table 4).

All studied patients had hydration management at primary care before referral. This likely explains the near-normal hematocrit values observed in our patients. However, hematocrit was higher at admission than at discharge (Supplementary Fig. S1) and hematocrit in patients aged 7-15 years increased $12.5 \%$ above normal for the age (Table 4), similar to another study (Bodinayake et al. 2018).
A limitation of our study is that the DENV serotype was not determined, thus we cannot discard that a particular serotype was associated with severity in either PI or SI. We know that serotypes DENV-1 and DENV-2 have predominated alternately in the three recent dengue outbreaks in the AtlixcoIzucar Valley with DENV-1 predominating and DENV-4 reported for the first time in the outbreak studied here (SSA 2016).

\section{Conclusions}

In this study PI was detected in $23 \%$ of patients requiring hospitalization in a Mexican region of low and recent DENV incidence. These results provide evidence that PI dengue can include DHF-II and III or SD cases, during outbreaks, which increases the burden to health systems. More studies to determine the proportion and characterize the severity of PI dengue and its related mechanisms are needed in Latin America and worldwide.

\section{Author Disclosure Statement}

No conflicting financial interests exist. 


\section{Funding Information}

This study was supported by Benemerita Universidad Autonoma de Puebla (VIEP-BUAP-100336999) and Instituto Mexicano del Seguro Social (grants FIS/IMSS/PROT/G11/ 980, FIS/IMSS/PROT/G13/1244 and CTFIS/10RD/12/2011). J.R.-L. has a research fellowship from Foundation IMSS Asociacion Civil.

\section{Supplementary Material}

Supplementary Figure S1

\section{References}

Abello JE, Gil Cuesta J, Cerro BR, Guha-Sapir D. Factors associated with the time of admission among notified dengue fever cases in region VIII Philippines from 2008 to 2014. PLoS Negl Trop Dis 2016; 10:e0005050.

Bodinayake CK, Tillekeratne LG, Nagahawatte A, Devasiri V, et al. Evaluation of the WHO 2009 classification for diagnosis of acute dengue in a large cohort of adults and children in Sri Lanka during a dengue-1 epidemic. PLoS Negl Trop Dis 2018; 12:e0006258.

Brady OJ, Gething PW, Bhatt S, Messina JP, et al. Refining the global spatial limits of dengue virus transmission by evidencebased consensus. PLoS Negl Trop Dis 2012; 6:e1760.

Constantine GR, Rajapakse S, Ranasinghe P, Parththipan B, et al. Hypocalcemia is associated with disease severity in patients with dengue. J Infect Dev Ctries 2014; 8:1205-1209.

da Silva NS, Undurraga EA, Verro AT, Nogueira ML. Comparison between the traditional (1997) and revised (2009) WHO classifications of dengue disease: A retrospective study of 30 670 patients. Trop Med Int Health 2018; 23:1282-1293.

Dantés HG, Farfán-Ale JA, Sarti E. Epidemiological trends of dengue disease in Mexico (2000-2011): A systematic literature search and analysis. PLoS Negl Trop Dis 2014; 8:e3158.

Guerra-Nunes PC, de Filippis AMB, Lima MQDR, Faria NRDC, et al. 30 Years of dengue fatal cases in Brazil: A laboratorial-based investigation of 1047 cases. BMC Infect Dis 2018; 18:346.

Guilarde AO, Turchi MD, Siqueira JB, Jr., Feres VC, et al. Dengue and dengue hemorrhagic fever among adults: Clinical outcomes related to viremia, serotypes, and antibody response. J Infect Dis 2008; 197:817-824.

Halstead SB. Dengue antibody-dependent enhancement: Knowns and unknowns. Microbiol Spectr 2014; 2:1-18.

Halstead S, Wilder-Smith A. Severe dengue in travellers: Pathogenesis, risk and clinical management. J Travel Med 2019; 26:pii:taz062.

INEGI. Dirección General de Geografía y Medio Ambiente. Catálogo Único de Claves de Áreas Geoestadísticas Estatales, Municipales y Localidades. 2017. Available at http://inegi .org.mx/geo/contenidos/geoestadistica/catalogoclaves.aspx

López-Santiago N. Blood cytometry. Acta Pediatr Mex 2016; 37:246-249.

Oliveira RA, Silva MM, Calzavara-Silva CE, Silva AM, et al. Primary dengue hemorrhagic fever in patients from northeas of Brazil is associated with high levels of interferon- $\beta$ during acute phase. Mem Inst Oswaldo Cruz 2016; 111:378-384.

Posadas-Mondragón A, Aguilar-Faisal JL, Chávez-Negrete A, Guillén-Salomón E, et al. Indices of anti-dengue immunoglobulin $\mathrm{G}$ subclasses in adult Mexican patients with febrile and hemorrhagic dengue in the acute phase. Microbiol Immunol 2017; 6:433-441.
SSA (Secretaría de Salud). Dirección General de Epidemiología Panorama Epidemiológico de Dengue 2014 - Semana Epidemiológica 52 [Internet]. 2014. Available at https://gob.mx/salud/ documentos/direccion-general-de-epidemiologia-panoramaepidemiologico-de-dengue-2014-semana-epidemiologica-52

SSA (Secretaría de Salud). Panorama Epidemiológico de Dengue 2016 [Internet]. 2016. Available at: https://gob.mx/salud/ acciones-y-programas/direccion-general-de-epidemiologiapanorama-epidemiologico-de-dengue

Soo KM, Khalid B, Ching SM, Chee HY. Meta-analysis of dengue severity during infection by different dengue virus serotypes in primary and secondary infections. PLoS One 2016; 11:e0154760.

Souza LJ, Alves JG, Nogueira RM, Gicovate Neto C, et al. Aminotransferase changes and acute hepatitis in patients with dengue fever: Analysis of 1,585 cases. Braz J Infect Dis 2004; 8:156-162

Stanaway JD, Shepard DS, Undurraga EA, Halasa YA, et al. The global burden of dengue: An analysis from the Global Burden of Disease Study 2013. Lancet Infect Dis 2016; 16 : 712-723.

Torres-Galicia I, Cortés-Poza D, Becker I. Dengue in Mexico: Increase in the juvenile population during the last decade. Bol Med Hosp Infant Mex 2014; 71:196-201.

Tomashek KM, Wills B, Lum LCL, Thomas L, et al. Development of standard clinical endpoints for use in dengue interventional trials. PLoS Negl Trop Dis 2018; 12:e0006497.

Trompetero-González AC, Cristancho-Mejía E, BenavidesPinzón WF, Serrato-Roa M, et al. Behavior of hemoglobin concentration, hematocrit and oxygen saturation in Colombian university population at different altitudes. Nutr Hosp 2015; 32:2309-2318.

Vázquez-Pichardo $M$, Rosales-Jiménez $C$, Núñez-León A, Rivera-Osorio P, et al. Dengue serotypes in Mexico during 2009-2010. Bol Med Hosp Infant Mex 2011; 68:103-110.

Wash R, Soria CD. True blood: Dengue virus evolution. Nat Rev Microbiol 2015; 13:662.

WHO. Dengue Haemorrahagic Fever. Chapter 2. Clinical Diagnosis. Second edition. Geneva, Switzerland: WHO, 1997:12-23.

WHO. Dengue: Guidelines for Diagnosis, Treatment, Prevention and Control. Chapter 2: Clinical Management and Delivery of Clinical Services. New edition, Geneva, Switzerland: WHO, 2009a:52-53.

WHO. Dengue: Guidelines for Diagnosis, Treatment, Prevention and Control. Chapter 4: Laboratory Diagnosis and Diagnostic Test. New edition, Geneva, Switzerland: WHO, 2009b:91-107.

Wichmann O, Hongsiriwon S, Bowonwatanuwong C, Chotivanich $\mathrm{K}$, et al. Risk factors and clinical features associated with severe dengue infection in adults and children during the 2001 epidemic in Chonburi, Thailand. Trop Med Int Health 2004; 9:1022-1029.

Address correspondence to: Francisca Sosa-Jurado

Laboratorio de Biología Molecular y Virología Centro de Investigación Biomédica de Oriente del Instituto Mexicano del Seguro Social en Metepec Km 4.5 Carretera Federal Atlixco-Metepec Metepec, Atlixco Puebla, CP 74360 México

E-mail: sosajurado@hotmail.com 